\title{
Can a video game with a fictional minority group decrease intergroup biases towards non-fictional minorities? A social neuroscience study.
}

\author{
Guillaume P. Pech ${ }^{1} \&$ Emilie A. Caspar ${ }^{1,2}$ \\ ${ }^{1}$ Center for Research in Cognition and Neuroscience, Université libre de Bruxelles, Belgium \\ ${ }^{2}$ Social \& Moral Brain Lab, Department of Experimental Psychology, Ghent University
}

\begin{abstract}
A critical scientific and societal challenge consists in developing and evaluating interventions that reduce prejudice towards outgroups. Video games appear to be a promising method but a number of falls in the current scientific literature prevents to fully understand the potential sizeable impact of video games on reducing prejudice. The present study investigated to what extent a video game designed to reduce prejudice towards minorities in a fictional society has the potential to reduce prejudice towards non-fictional minorities. Participants played either a recently developed game designed to reduce prejudice towards non-fictional minorities (hereafter referred to as the test game) or a control game. After playing at home, participants performed two tasks in a lab context. We observed overall a positive effect of playing the test game compared to the control game on attenuating prejudice towards an outgroup individual. We indeed observed that players of the control game had more midfrontal theta activity, reflecting more cognitive conflict, when they acted prosociality towards the outgroup participant and a lower neural response to the pain of the outgroup participant compared to the ingroup participant. These effects were attenuated for players of the test game. We also observed that players of the test game had a higher sense of agency when they decided to help the outgroup participant compared to when they did not help the outgroup participant, an effect not observable in players of the control game. These results are promising as they support evidence that using fictional characters in video games may induce positive changes towards non-fictional individuals.
\end{abstract}

Keywords: Video games; prejudice; cognitive conflict; empathy for pain; sense of agency

\section{Corresponding author}

Prof. Emilie Caspar

Department of Experimental Psychology, Ghent University

Henri Dunantlaan, 2

9000, Ghent

Belgium

Mail: Emilie.Caspar@UGent.be 


\section{INTRODUCTION}

Developing cooperative social relationships between groups is a fundamental challenge for human societies, especially in the context of mundialization, where people from diverse background and culture are brought to live together. A critical scientific and societal challenge consists therefore in developing and evaluating interventions that improve social relationships between groups and reduce prejudice towards people considered as 'outgroup' (Paluck et al., 2021).

Prejudice can be defined as more negative attitudes towards another group (i.e. the outgroup) and more positive attitudes towards one's own group (i.e., the ingroup) (Greenwald $\&$ Pettigrew, 2014). Prejudice can take many forms, ranging from negative thinking, antisocial attitudes, reduced prosociality, social exclusion, hate speech or, in its more extreme forms wars and genocides. The scientific literature has witnessed the development of a high range of different approaches, all aiming to reduce prejudice between groups (Paluck \& Green, 2009a). They range from meditation- and mindfulness-based mental training interventions (Berry et al., 2021), contact with the outgroup (Ellison et al., 2011; Miller \& Brewer, 1986; Tajfel, 1970), raising consciousness (Blair, 2002), instructions to be empathetic when reading about everyday discrimination (Stephan \& Finlay, 1999), or entertainment activities, such as reading (Cameron et al., 2006; Wham \& Others, 1996), listening to educational radio soaps (Paluck \& Green, $2009 b$ ) or playing video games (Adachi, Hodson, \& Hoffarth, 2015).

Among the different intervention methods used, video games appear to be one of the most promising. First, video games are the fastest growing form of entertainment (Adachi, Hodson, \& Hoffarth, 2015), with billions of gamers across the world. Second, several studies have shown that imagining contact with an outgroup is sufficient to reduce prejudice towards those outgroup members (Cameron et al., 2006; Crisp \& Turner, 2009). Thus, video games have the potential to be a critical method for fostering contacts between individuals from diverse groups and to reduce intergroup biases (Stiff \& Bowen, 2016; Stiff \& Kedra, 2020). Third, young adults are highly vulnerable to the xenophobic narratives towards outgroup and violent practices spread by extremists (Jahnke et al., 2020). Young adults are also the biggest users of social media and online games (Robinson \& Whittaker, 2021). On the Internet, violent extremists often use online social networks and platforms to incite violence, recruit vulnerable individuals and raise funds (Robinson \& Whittaker, 2021). For instance, modified versions of games have famously been used for jihadist recruitment, but also right-wing extremist talk is ripe in community websites and among the "guilds" and "crews" of a popular shooting game. By using these similar platforms (i.e. online video games) to promote counter-narratives and stimulating positive behavior change in the audience, hope is raised for providing a powerful tool to counter-radicalization efforts.

Past scientific literature has started to investigate how the intergroup context in video games influence intergroup attitudes and behaviors in experimental sets-up. Saleem and Anderson (2013) observed that playing a violent video game in which the enemy character was an outgroup member (i.e. Arab) increased prejudice attitudes towards Arabs among American participants. Adachi, Hodson, Willoughby, et al. (2015) found that playing a violent video game cooperatively with an outgroup member for 12 minutes reduced outgroup prejudices. Stiff and Kedra (2020) showed that playing a casual video game with an outgroup member increased positivity towards members of that group. Playing video games in an intergroup context thus seems to be a promising tool. However, a number of falls in the actual literature prevent to fully understand the potential sizeable impact of video games on reducing intergroup biases in diverse human societies. 
First, the huge majority of past studies on video game and prejudice used self-reported outcomes, such as questionnaires, to evaluate the intergroup biases (Adachi et al., 2016; Saleem \& Anderson, 2013; Stiff \& Kedra, 2020), without controlling for social desirability. With selfreported outcomes, participants can exaggerate the influence of the intervention in order to please the experimenter (Paluck et al., 2021). More objective methods, for instance relying on neuro-cognitive measurements, are unfortunately almost inexistent in the current scientific literature (Paluck et al., 2021). Second, most studies lack direct comparison with other video games (Adachi, Hodson, Willoughby, et al., 2015; Stiff \& Kedra, 2020), thus precluding to isolate the effect of a specific game on intergroup biases or a general effect of playing video games. Third, past studies on the effect of video games on prejudice attitudes towards outgroup largely used a gameplay that targeted a real human individual as the outgroup enemy or rival, such as someone with a different skin color (Vang \& Fox, 2014; Yang et al., 2014) or a different religion (Saleem \& Anderson, 2013). As video games are used all over the world, using real individuals as the enemy character can have negative influences on individuals who are actually part of this 'enemy' group, by increasing their perception of exclusion and stigmatization (Cary, 2017; Ortiz, 2019). To evaluate a potential sizeable impact of video games across all human societies to reduce intergroup biases, fictional characters should better be used.

The present study aims to evaluate the effect of an online video game (hereafter referred to as the test game), which is a prototype edutainment intervention designed to reach youth vulnerable to radicalization. It is a Massive Online Battle Arena (MOBA) game that shows a fictional society consisting of two groups, the Etanoreans, the majority group, which owns all the technological advancements, and the Oldarins, the minority group, which is considered by the Etanoreans as inferior and feeble-minded. When the society experiences an existential energy crisis, an unscrupulous leader convinces the Etanoreans that the Oldarins are responsible for the crisis. To "appease the gods" he makes the two groups confront each other during arena battles. Players play the role of Esp, a young Etanorean who will undergo experiences that make him realize that the Oldarins are not responsible for the degradation of the society and eventually start defending them. Thus, the game has been conceived to create a fictional scenario where insecurity prompts players to experience scapegoating, leading them into conflicts with the minority group. Then, through the messaging delivered implicitly throughout the game, players start gaining awareness regarding how leaders can exploit their fears for their own power without helping them solve the real cause of their fears- the goal being to reduce prejudiced attitudes. Creating only implicit messaging is important here as a strategy employed by the intervention to prevent reactance - a frequent problem encountered by anti-radicalization projects that find that they do not reach the intended target audience when that audience perceives 'open' messaging as an attempt by an 'opposing' side to change their attitudes. Hence this intervention aims to avoid any feeling of 'being lectured to' which could turn the target audience away from playing the intervention.

Participants were invited to play test game or another control game, which has a relatively similar gameplay but without any specific messaging, between 2.5 to 4 hours at home. Then, they were invited to come at the lab and were told that they would be performing different tasks with three other (fake) participants present in different experimental rooms. Purposely, those three other participants had two representants of the majority group where the study was conducted (i.e. European Caucasian) and one representant of a minority group (i.e. Afro descendant). Using behavioral and electroencephalography (EEG) measurements, we assessed prejudice attitudes towards the representant of the minority group (=outgroup) compared to the majority group (=ingroup) through two different prosocial tasks previously used in the literature: a costly helping task and an intended prosociality task. Those two tasks differ in the extent to which participants may feel close or distant from the outcomes of their action, as the 
tasks respectively involve taking decisions that have a direct consequence on someone else (i.e. a physical pain), or taking decisions that have only imagined consequences on someone else.

Costly helping tasks commonly involve losing a monetary gain or enduring physical pain to prevent someone else from receiving a painful stimulation. In a previous study (Hein et al., 2010), the authors observed that soccer fans were less likely to endure physical pain to prevent the soccer fan of a rival team (=outgroup) to receive a painful shock compared to another soccer fan supporting the same team (=ingroup). The Magnetic Resonance Imagery (MRI) results showed that a key neural process to explain such results was empathy. Empathy refers to our capacity to imagine and understand what others feel. Previous MRI studies showed that experiencing painful stimulations and empathizing with the same pain delivered to others evoke a brain activation pattern overlapping with in the anterior insula (AI) and in the anterior cingulate cortex (ACC) (see Lamm et al., 2011; Timmers et al., 2018 for reviews). These results suggest that we are able to understand and imagine what others feel since we can process that pain within our own pain system. In the study of Hein et al. (2010), the authors observed that activity in the left anterior cingulate (left AI) cortex was less activated when participants saw the outgroup receiving the pain compared to the ingroup. Further, activity in the left AI predicted helping behavior for the ingroup (Hein et al., 2010). This result is consistent with other studies showing a reduced neural response for the pain of outgroup individuals compared to ingroup individuals (Caspar, et al., n.d.; Cikara et al., 2014; Han, 2018). Based on the study of Hein et al. (2010), we used in the present study a costly helping task in which participants had to decide to drop a part of their monetary gain to prevent the other (fake) participants to receive a mildly painful shock on their hand. We predicted less costly helping towards the outgroup than towards the two ingroup participants, an effect potentially attenuated after playing the test game. In the present study, we used electroencephalography (EEG) to record the neural response to the pain of others. In EEG studies, a recent meta-analysis suggested that the P3 and the Late Positive Potential (LPP) over the centro-parietal electrodes are robust to measure the neural empathic response to the pain of others (Coll, 2018). We predicted that the amplitude of the P3 and LPP would be reduced for the outgroup participant compared to the ingroup participants. This difference could also be attenuated for players of the test game, with less differences between outgroup participant and the ingroup participants.

In the costly helping task, we also evaluated to what extent participants feel a sense of agency when they decide to help the outgroup or the ingroup participants. The sense of agency is the feeling that we are the authors, and thus potentially responsible for, our actions and their consequences (Gallagher, 2000). In the literature, researchers have largely used an implicit method relying on time perception (Haggard, 2017) to avoid biases in explicit reports, such as social desirability (Yoshie \& Haggard, 2013). In classic time perception tasks, participants have to estimate the duration of a time interval that elapsed between an action (e.g. pressing a button) and its consequences (e.g. hearing the beep it produces). Results typically show that participants tend to estimate time intervals as shorter when the action is performed voluntarily compared to a condition in which the action is performed involuntarily (Moore \& Haggard, 2010), an effect referred to as temporal binding. It has been concluded that sense of agency modulates time perception, by reducing it. A previous study showed that people usually experienced a higher sense of agency, as indexed by a lower estimation of time intervals, when they act prosocialy and decide not to send a painful shock to another participant compared to sending a painful shock (Caspar et al., 2018). Here, we predicted that our participants would experience less agency when they do not prevent the outgroup participant to receive the shock compared to the ingroup participants, an effect again potentially reduced after playing the test game.

Intended prosociality was measured by presenting to our participants three different prosocial scenarios from daily life, such as giving $€ 2$ to offer a bus ticket or taking time to comfort someone, based on a method used in another study (Pech \& Caspar, 2022). The pictures 
of the three (fake) participants were presented by pairs and participants had to decide as fast as possible who the beneficiary of the prosocial action was. In a previous study conducted in Rwanda on former genocide perpetrators and survivors (Pech \& Caspar, 2022), results indicated that participants tend to favor their own ingroup compared to the outgroup. We expected that participants would choose more frequently the ingroup participants compared to the outgroup participant, an effect attenuated after playing the test game.

A concern has nonetheless been raised in the literature regarding the fact that participants may not be fully sincere in imagined scenarios and show a high prosociality towards outgroup individuals to appear fairer to the experimenter (Amodio, Devine, et al., 2008). In the neuroscientific literature, a promising approach consists in evaluating to what extend the selected behaviors implied or not a high cognitive conflict (Berns et al., 1997; Nieuwenhuis et al., 2001). Usually, a higher cognitive conflict involves that the selected action was not the most natural to select compared to the other actions (Amodio, Devine, et al., 2008). In the intended prosociality task, we thus further measured to what extent selecting the outgroup induced a higher cognitive conflict compared to selecting the ingroup and if playing the test game reduced the conflict when selecting the outgroup. Several methods to measure the intensity of the conflict experienced by participants when selecting an action have been reported in the literature. It has been repeatedly shown that decisions that are more difficult to take involves longer reaction times before selecting the action than easier decisions (Cohen \& Donner, 2013; Greene et al., 2004). Using electroencephalography, past literature has shown that a stronger conflict elicits a higher activity in the midfrontal theta $(4-8 \mathrm{~Hz})$ compared to low conflicts (Cavanagh \& Frank, 2014; Cohen \& Cavanagh, 2011; Cohen, 2014; Cohen \& Ridderinkhof, 2013; Nigbur et al., 2012).

In the literature on prejudice, several studies have shown that electrophysiological measurements of cognitive conflict indicate a higher conflict when participants have to inhibit prejudice towards outgroups compared to when they do not have to inhibit prejudice (Amodio, Devine, et al., 2008; Amodio et al., 2006; Amodio \& Swencionis, 2018; Bartholow et al., 2006; Correll et al., 2006). Experiencing or not a conflict may be of important to change behaviors. Amodio et al. (2008) indeed showed that people with lower conflicts when inhibiting to stereotype outgroup members have more facility to further change their behaviors towards those outgroup members. In another study (Pech \& Caspar, 2022), the results indicated that conflict, as measured with midfrontal theta power and reaction times, was higher when participants selected the outgroup compared to the ingroup. In the intended prosociality task, we thus used reaction times and midfrontal theta activity as indirect measurements of cognitive conflict in order to evaluate to what extent choosing to act in a prosocial way towards an outgroup individual involves a higher cognitive conflict than choosing to act in such a way towards an ingroup individual. We expected to observe a higher conflict when participants selected the outgroup compared to selecting the ingroup, an effect potentially attenuated for players of the test game.

\section{METHOD}

Participants. We recruited 65 male participants, aged between 18 and 36 years old with no preference for dominance handing. As no previous studies used a similar experimental approach, we used a small-to-medium effect size f of 0.175 to calculate the sample size (Faul et al., 2007). To achieve a power of .90 for this effect size, the estimated sample size was 54 for 2 groups tested with a 2-level within-subject factor (i.e., Individual) and a 2-level betweensubject factor (i.e., Group). We increased the sample size to prevent the loss of data in the costly helping task, as never helping or always helping would have prevented to compute event-related potentials associated with the visualization of the pain. We recruited participants through 
advertisements on social medias and on job recruitment websites. Inclusion criteria included being able to play video games and having a haircut that fits with electroencephalography (EEG) recordings (i.e., no dreadlocks, not bold). Exclusion criteria were determined prior the data acquisition. They included: (1) failure to discriminate between time intervals, (2) bad signal-to-noise ratio in EEG, (3) and not paying attention to the task. For time intervals (see exclusion criteria 1), to identify participants for whom the action-tone intervals did not gradually increase with action-tone intervals, we performed a linear trend analysis (LTA) with Sieve Bootstrap Based Test for the Null Hypothesis of no Trend (Hess et al., 2001) in order to ensure that participants' estimations of time intervals followed the real time intervals and followed a linear trend (Hess et al., 2001). The data of 7/65 participants were excluded due to a non-significant LTA. Other data were kept for those participants. Regarding EEG recordings, we had to exclude 4 participants due to a bad signal-to-noise ratio (i.e., bad signal on the electrodes of interest or noisy reference electrodes). Further, 21 participants did not send any shocks or sent shocks all the time, thus precluding the analysis of their data associated with witnessing the pain of the other individual in the costly helping task. Again, the other data of those participants were kept. One participant was fully excluded due to a technical problem during the recording. For the test game, there were 33 remaining participants (mean age: 23.21 , $\mathrm{SD}=4.35$ ) and for the control game, there were 31 remaining participants (mean age: 22.45, $\mathrm{SD}=2.80$ ). All participants were paid 30 euros for their participation even if they were instructed that they could increase this monetary gain based on their decisions during the task. The study was approved by the local ethical committee of the Universite libre de Bruxelles (reference number: 2021/696).

\section{Procedure \& Material.}

Participants were randomly assigned to play either the test game or the control game (name withheld for the confidentiality of the intervention but available upon request) at home for 2.5 to 4 hours. They were requested to send us a print screen of their Steam account to confirm that they finished the storyline of the game or played for the expected duration before coming to the lab for the experiment.

When participants came at the lab 2 to 4 days after playing the game, we first explained the two different tasks (i.e. the 'Costly helping task' and the 'Intended Prosociality task', see below) and told them that we had to synchronize the timing of the experiment with three other participants participating in the experiment at the same time. As we sought to evaluate how playing a specific video game would decrease prejudice towards outgroups, we had to include other individuals in the study, which would be representative of the ingroup majority in Europe (i.e. Caucasian) or of outgroup minorities (i.e. Afro descendant). To avoid participants guessing that we were evaluating their behaviors towards ingroup or outgroup individuals, we did not include only a single Caucasian participant versus a single afro-descendant participant, which would have been a too obvious experimental manipulation. Rather, we included 3 other individuals, two Caucasian male individuals and one Afro descendant male individual. As we had to ensure that our participants believed that they were doing the task at the same time as the other (fake) individuals, which were presented as other participants, we told them that for anonymity reasons, each participant would be placed in different experimental rooms on different floors of the same building. We already told them in the recruitment emails to avoid mixing floors in order to ensure that their anonymity would be protected and to come at the exact planed schedule as we had to synchronize the tasks between the different participants.

After signing the consent forms, we installed the electroencephalogram (EEG) and determined their individual pain threshold for the electrical stimulation, as described in Caspar et al. (2016). Two electrodes were placed on the participants' left hand on the abductor pollicis muscle in order to produce a clear and visible muscle twitch and the threshold was increased 
by steps of $1 \mathrm{~mA}$ until a mildly painful stimulation was achieved. The pain threshold was determined by asking a series of questions to the participants about their pain perception during the calibration (1. «Is it uncomfortable? »-2. "Is it painful? »-3. "Could we increase the threshold? »). We told our participants that the same procedure would be applied to the other participants as well and that the pain threshold will remain similar throughout the entire experiment.

Then, participants were provided explanations about the two different tasks. In the 'Costly helping task', participants observed through a video displayed on the top of their screen the hand of one of the three other individuals, see FIGURE 1C. We told our participants that the videos were displayed in real-time for analyzing in real-time their brain activity when witnessing the consequences of their actions. We also told them that the other participants would see their own hand when they would be doing the costly helping task as well. We thus also installed a webcam in front of the hand of the participants and told them not to move. In reality, the webcam was not connected, and the videos displayed on the screen were prerecorded. Two of those videos showed the hand of two Caucasian male individuals and the third video showed the hand of an Afro descendant male individual. On the bottom of the screen, below the video, was displayed a sentence stating, 'Do you want to spend $0.05 €$ to avoid the other participant to receive the shock?'. Two possible answers were displayed below: a 'YES' displayed in green and associated with a picture of no shock and a ' $N O$ ' displayed in red and associated with a picture of a shock. The 'YES' and 'NO' answers were presented in a randomized position either on the right or on the left of the screen to avoid motor habituation. Participants answered with the left or the right arrow on the keyboard to select their answer. We instructed participants that if they answered 'YES', they would lose $€ 0.05$ but would prevent the other participant from receiving the shock. In the case participants answered 'NO', they were instructed that they would keep the $€ 0.05$ and that the other participant would receive the shock. Participants could observe the consequences of their decision through the (fake) realtime video displayed on the screen which showed a hand connected to two electrodes. The hand showed a visible muscular contraction if a shock was delivered and no muscular contraction if no shocks were delivered. No matter the decision of the participant, a tone $(550 \mathrm{~Hz}, 500 \mathrm{~ms})$ was displayed after each keypress and a random time interval of $800,1,100$ or 1,400 ms. Participants had to estimate the time interval that elapsed between their keypress and the tone. If a shock was delivered, the shock was displayed exactly at the same time as the tone. We instructed them that the time intervals would vary between 500 and 1,500 ms. An analogue scale ranging from 500 to $1,500 \mathrm{~ms}$ was displayed on the screen 2 seconds after the keypress. Participants were told to click with the mouse on the scale according to their estimation of the time interval. There were 60 trials for each individual presented, thus resulting in a total of 180 trials for the three individuals. 


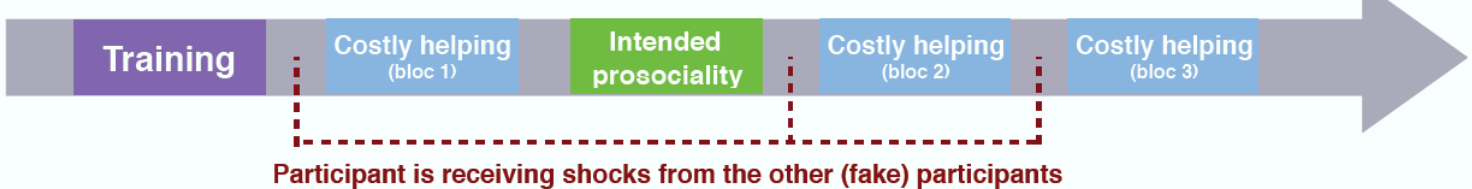

Participant is receiving shocks from the other (fake) participants

B TRAINING
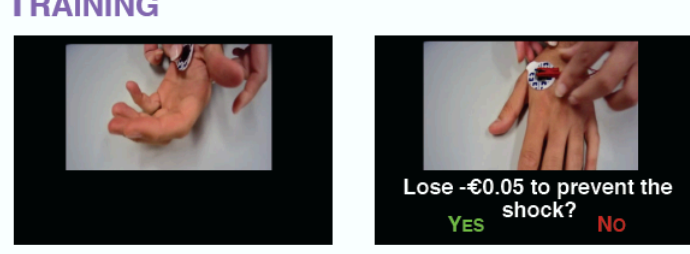

Beep

(+ shock)

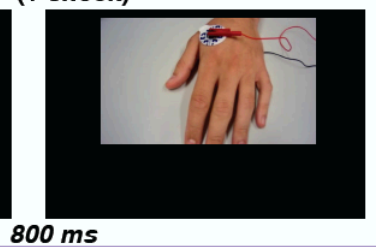

Time that elapsed between the keypress and the tone?

Until keypress

$1500 \mathrm{~ms}$

$1.5 \mathrm{~s}$

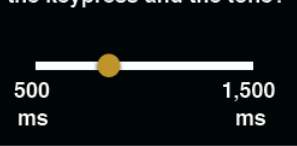

Beep

C COstLy helping tAsK
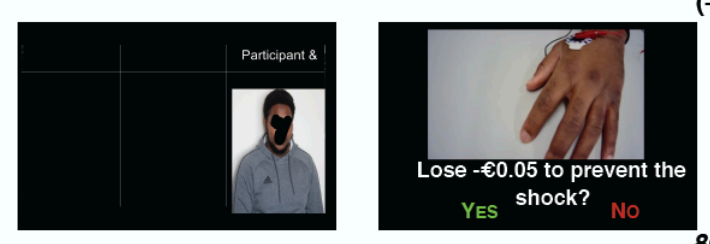

(+ shock)

Until mouse click

\section{Until keypress}

Until keypress
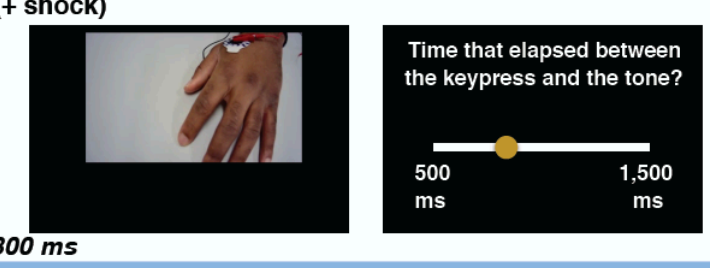

Until mouse click

\section{INTENDED PROSOCIALITY TASK}
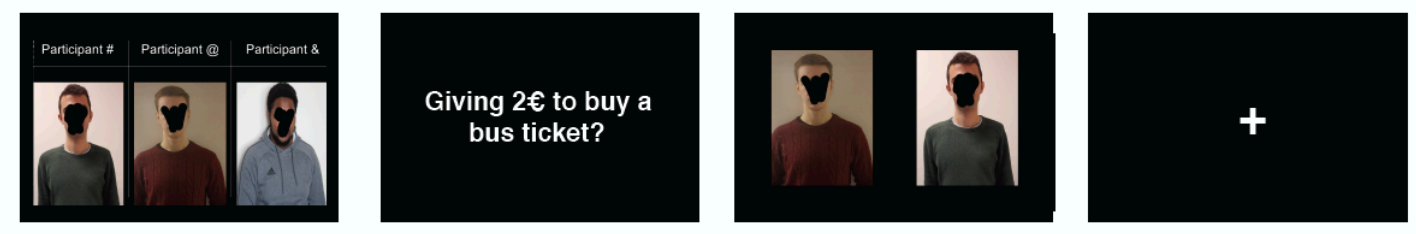

Until keypress

Until keypress

Until keypress

$1.5 \mathrm{~s}$

FIGURE 1. A) Schematic representation of the timeline of the experiment. B) Schematic representation of the training. While practicing the interval estimate task, participants could witness the video of the hand of another (fake) participant being installed to increase the reality of the task. C) Schematic representation of the costly helping task. Participants were presented one of the three other (fake) participants and had to decide on each trial to help that participant and avoid him to receive a mildly painful shock in exchange of dropping $€ 0.05$. D) Schematic representation of the intended prosociality task. On each trial, participants were presented pairs of individuals and they had to select who would benefit from the prosocial action. The picture displays an example of an ingroup $v s$ ingroup pair.

In the 'Intended Prosociality task', participants were presented three different prosocial scenarios in which they had to choose one out of two pictures of a pair of individuals, see FIGURE 1D. On those pictures, participants could see the upper part of the body of the other individuals, with their faces blurred, as mentioned in the emails during the advertisement. To justify the fact that we had the pictures of the other participants, we asked our participants to also send us a picture of them with a blurred faced and told them that this picture would be uploaded on the computer of the other participants and used during the experiment. We used three different scenarios including different types of prosocial intentions instead of a single one in order to prevent monotony during the task. In one scenario, participants had to decide to which of the two individuals presented they would give $2 €$ to pay them a bus ticket. In another scenario, participants had to decide to which of the two individuals presented they would help to move. In a third scenario, participants had to decide to which of the two individuals presented they would give time to comfort at the emotional level. After being presented the scenario, 
participants were presented 6 different combinations of pairs of pictures showing the other individuals. Those combinations included either two different individuals (e.g., the picture of one of the Caucasian male individual VS the picture of the Afro-descendant male individual) (Free condition) or two times the same individual (e.g., the picture of the Afro-descendant male individual VS the picture of the Afro-descendant male individual) (Forced condition). When the pairs of pictures were presented, participants were told to press either the left or the right arrow as fast as possible to select their answer. The three different scenarios were presented 7 times each, systematically followed by the 6 different pair combinations presented in a randomized order. In total, there were 126 trials, with 21 trials for each combination.

The two tasks were presented in a semi-randomized order for each participant, see FIGURE 1A. All participants started with a training for estimating the intervals between their keypress and the resulting tone, as used in the costly helping task, see FIGURE 1B. There were 10 trials in the training, but the trials could be repeated until participants were able to discriminate correctly between the different time intervals. During the training, participants saw the same screen as in the costly helping task, but the video displayed the preparation of the electrodes installed on the hand of another participant by another experimenter. This video was used to reinforce the belief that there were actually other participants being prepared at the same time for the same task. At the end of the training session, we informed our real participant that one of the other participants was ready for the costly helping task and that he would first be the one receiving or not the shocks. We also told our real participant that we would not reveal who the other participant completing the costly helping task was, so not to bias their decisions when they perform the task themselves on the other participants. Our participants received 6 shocks with a random time interval between each shock for 4 minutes. Each time we told our participants that another participant was performing the costly helping task, there were 6 shocks sent at a random time interval during 4 minutes in order to make them believe that another individual was really performing the task. This also avoided to create differences between the three other individuals. The 6 shocks were decided to maximize the ratio between accepting to drop money for preventing a shock to happen or not based on a pilot study. After receiving the shocks, participants were invited to start a first block of the costly helping task. There were presented one of the three other individuals, randomly selected to perform the task. After the first block of the costly helping task, participants performed the intended prosociality task. At the end of the task, they received a questionnaire to fill in (see Supplementary Information S1) and received 6 shocks again at a random time, as we told them that another participant was performing the costly helping task. Then, participants performed the last two blocks of the costly helping task, on the two other individuals. At the end of the task, we again gave our participants a questionnaire to fill in and again, we told them that another participant was performing the costly helping task.

\section{Data analysis}

Trials rejection. In the two tasks trials which were either faster than $350 \mathrm{~ms}$ (Semmelmann \& Weigelt, 2017) and slower than $20 \mathrm{~s}$ were removed. We used longer minimum and maximum RT than in previous studies (i.e. $200 \mathrm{~ms}$, Cohen \& Donner, 2013) because the prosocial component in our task requires more time to select the answer than in reaction time tasks which involve neutral decisions. We also rejected responses deviating from more than 2.5 Median Absolute Deviation (Leys et al., 2013) in the interval estimation task for each participant.

EEG recordings. EEG data were acquired at 2,048 Hz from 32 channels placed according to the international 10-20 system using Biosemi equipment (see http://www.biosemi.com for hardware details). Four additional electrodes were used to acquire horizontal eye movement and mastoids signals. All the data were recorded by the Actiview software. To filter and clean the data, we used the Matlab r2018a software and the fieldtrip toolbox (Oostenveld et al., 2011). 
We applied a bandpass filter between $0.1 \mathrm{~Hz}$ and $30 \mathrm{~Hz}$. Different baselines were used depending on the analysis and are further specified below. To re-reference the signal, we subtracted the signal of the two mastoid electrodes to each scalp electrode. Since our participants were not in a Faraday Cage, we performed a spectrum interpolation between the 49 $\mathrm{Hz}$ frequency band and the $51 \mathrm{~Hz}$ frequency band to remove the $50 \mathrm{~Hz}$ noise. To remove artefacts due to eye movements (i.e. saccades and eye blinks), we first ran an Independent Component Analysis (ICA) on 30 components. Then, we removed the remaining artefacts based on visual inspection. In average $2.66(\mathrm{SD}=.122)$ trials were removed in the intended prosociality task and $3.1(\mathrm{SD}=.213)$ trials were removed in the costly helping task.

Event-related potential (ERP) analysis. In the costly helping task, we measured the amplitude of the P3 and the LPP study (Coll, 2018) across Cz and Pz. According to Cheng and colleagues (2014), we divided the LPP into an early (eLPP) and a late (ILPP) LPP. Based on the visualization of the grand averages, the $\mathrm{P} 3$ was measured as the most positive peak between the 250-400 ms time-window after the visualization of the shock. The early LPP and the late LPP were measured as the mean amplitude between the 380-800 ms time-window and the 800-1,200 ms time-window after the tone, respectively. The baseline was taken from 500 to $300 \mathrm{~ms}$ prior to the keypress. We conducted our analyses on the amplitude of the difference between shock and no shock trials (Shock - No Shock) for the P3, the eLPP and the ILPP as an indicator of the neural response to the pain of others.

Time-frequency representation (TFR) analysis. Based on previous studies, we measured the frontal midline theta frequency (FM $\theta$ ) over the $\mathrm{Fz}, \mathrm{Cz}, \mathrm{FC} 1$ and $\mathrm{FC} 2$ electrodes. We extracted the time-frequency power of each trial after calculating a Fast Fourrier transform (FFT) on our data and an FFT of a complex Morlet wave with the following parameters: frequency from 2 to $20 \mathrm{~Hz}$ with 80 bins spaced logarithmically and 4 to 14 cycles logarithmically spaced. Then, we used the Inversed Fast Fourrier Transform (IFFT) method on the multiplication of the computed FFT on our data and the FFT of the complex Morlet Wave. Epoching was performed by taking -2.5 to $1.5 \mathrm{~s}$ around the keypress (response-locked time window) and -1.5 to 2.5 around the presentation of the picture (stimulus-locked time window). All power values in the timefrequency representation were normalized to the average pre-stimulus baseline power at each frequency band. We used a decibel $(\mathrm{dB})$ transform for normalization $[\mathrm{dB}$ power $=10 \mathrm{x}$ $\log _{10}($ power/baseline)]. The baseline power was computed as the average power across all experimental conditions, from $1 \mathrm{sec}$ to $1.2 \mathrm{sec}$ after the keypress when TFR were responselocked and from -500 to $-300 \mathrm{~ms}$ when TFR were stimulus-locked. Based on visual inspection of the grand average data significatively superior at $p>.05$ (see FIGURE 2), FM $\theta$ was extracted from a $-420 \mathrm{~ms}$ to $0 \mathrm{~ms}$ time window before the keypress and from a $100 \mathrm{~ms}$ to $580 \mathrm{~ms}$ time window after the presentation of the picture. FM $\theta$ was extracted from a $2.9 \mathrm{~Hz}$ to $6.4 \mathrm{~Hz}$ windows before the keypress and from a $2.5 \mathrm{~Hz}$ to $8.1 \mathrm{~Hz}$ window after the presentation of the picture We systematically extracted the mean value in this time/frequency window for each participant. In the response-locked time window, we only selected a window prior to the keypress and did not consider the significant activation in the delta band after the keypress as we had no specific predictions. 

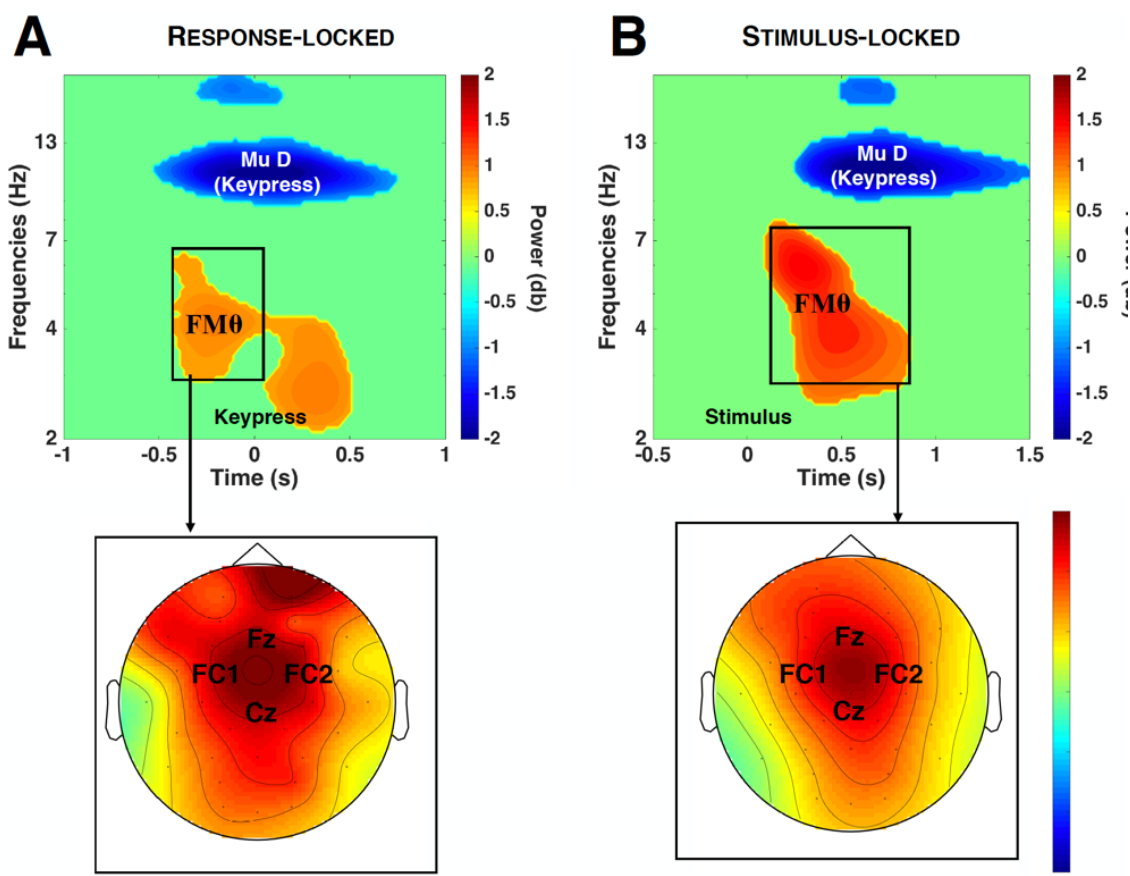

FIGURE 2. Response-locked (A) and Stimulus-locked (B) time frequency power plots for the 4 electrodes (Fz, $\mathrm{Cz}, \mathrm{FC} 1, \mathrm{FC} 2$ ). The significance level taken was $\mathrm{p}>.05$. Mu D represents the desynchronization in the Mu band $(8-12 \mathrm{~Hz})$, which is typical of movement execution (i.e. keypress).

\section{RESULTS}

We systematically combined the results of the two ingroup individuals by averaging their respective data as we did not expect differences between them. We systematically checked that there were actually no differences between them in each task before combining them. For each analysis, participants whose mean deviated more than 3SD based on the mean of all participants were considered as outliers and excluded (Seo, 2006). Our hypothesis predicted overall an 'outgroup' effect, that is, a higher prejudice towards the outgroup individual than towards the ingroup individuals. We also predicted that this effect would be attenuated for players of the test game compared to players of the control game. A significant interaction Group (test game, control game) and Individual (outgroup, ingroup) was thus not necessarily expected as we simply expected an attenuation of the outgroup effect for players of the test game. We thus systematically conducted paired comparisons between the ingroup individuals and the outgroup individual for each group of players, irrespective of the interaction given by the repeatedmeasure ANOVA.

\section{Costly helping task}

Prosocial behavior. We conducted a repeated-measures ANOVA with Individual (outgroup, ingroup) as within-subject factor and Group (test game, control game) as a between-subject factor on the number of helping actions. Results indicated a tendency for a main effect of individual $\left(\mathrm{F}_{(1,62)}=3.331, p=.073, \eta^{2} \mathrm{p}=.051\right)$, no main effect of group $(p>.3)$ and no interaction $(p>.3)$. Paired comparisons indicated that players of the test game helped more the outgroup individual $(35.6 / 60, \mathrm{SD}=16.48)$ than the ingroup individuals $(33.3 / 60, \mathrm{SD}=17.29)$. This difference was not significant for players of the control game $(p>.5)$.

Event-related potentials (ERPS). The EEG data of 31 participants were not analyzed: 5 because of too many visual artefacts, head artifacts and/or sweat artefacts, 25 because they delivered only a small number of shock $(\leq 5 / 60)$ or a high number of shocks $(\geq 55 / 60)$ to either one or all 
and ILPP when participants witnessed a shock on the other individuals' hand to when they did 2 not witness that shock in order to ensured that those ERPs are sensitive to seeing pain, see 3 FIGURE 3A\&B. To do so, we averaged the amplitude of each ERP across the individuals presented and the groups of players. Results confirmed that the amplitude was systematically higher when participants visualized a shock being delivered compared to when they did not visualize a shock being delivered for the P3 $\left(\mathrm{t}_{(33)}=4.769, p<.001\right.$, Cohen's $\left.\mathrm{d}=.806\right)$, the eLPP $\left(\mathrm{t}_{(33)}=13.412, p<.001\right.$, Cohen's $\left.\mathrm{d}=2.267\right)$ and the $\operatorname{ILPP}\left(\mathrm{t}_{(33)}=9.573, p<.001\right.$, Cohen's $\left.\mathrm{d}=1.618\right)$. The remaining analyses were conducted on the difference between the amplitude when participants visualized a shock compared to when they did not visualize a shock (Shock-No Shock trials).

We then conducted a repeated-measures ANOVA with Individual (outgroup, ingroup) as within-subject factor and Group (test game, control game) as a between-subject factor on the difference between Shock and No Shock trials. For the P3, none of the main effects or interactions were significant (all $p \mathrm{~s}>$.1), see FIGURE 3C. For players of the test game, paired comparisons indicated that there was no significant difference between the ingroup and the outgroup individuals $(p>.1)$. For players of the control game, the amplitude was lower for the outgroup individual $(-.30 \mu \mathrm{v}, \mathrm{SD}=4.23)$ than for the ingroup individuals $(2.47 \mu \mathrm{v}, \mathrm{SD}=3.41$, $\mathrm{t}_{(13)}=-2.186, p=.048$, Cohen's $\left.\mathrm{d}=-.584\right)$. For the eLPP, there was a significant main effect of individual $\left(\mathrm{F}_{(1,32)}=14.234, p=.001, \eta^{2}=.308\right)$, with a higher amplitude for the ingroup individuals $(8.80 \mu \mathrm{v}, \mathrm{SD}=3.83)$ than for the outgroup individual $(6.51 \mu \mathrm{v}, \mathrm{SD}=4.25)$. The main effect of group $(p>.1)$ and the interaction $(p>.1)$ were not significant. For players of the test game, paired comparisons indicated that there was no significant difference between the ingroup and the outgroup individuals ( $p>.09$ ). For players of the control game, the amplitude was lower for the outgroup individual $(5.84 \mu \mathrm{v}, \mathrm{SD}=5.47)$ than for the ingroup individuals $\left(9.33 \mu \mathrm{v}, \mathrm{SD}=4.21, \mathrm{t}_{(13)}=-3.247, p=.006\right.$, Cohen's $\left.\mathrm{d}=-.868\right)$. For the 1LPP, there was a main effect of individual $\left(\mathrm{F}_{(1,32)}=6.707, p=.014, \eta^{2} \mathrm{p}=.173\right)$, with a higher amplitude for the ingroup individuals $(6.24 \mu \mathrm{v}, \mathrm{SD}=3.96)$ than for the outgroup individual $(4.34 \mu \mathrm{v}, \mathrm{SD}=4.42)$. The main effect of group ( $p>.2)$ and the interaction $(p>.2)$ were not significant. For players of the test game, paired comparisons indicated that there was no significant difference between the ingroup and the outgroup individuals ( $p>.3$ ). For players of the control game, the amplitude was lower for the outgroup individual $(3.03 \mu \mathrm{v}, \mathrm{SD}=4.05)$ than for the ingroup individuals $(5.93 \mu \mathrm{v}$, $\mathrm{SD}=3.90, \mathrm{t}_{(13)}=-2.479, p=.028$, Cohen's $\left.\mathrm{d}=-.663\right)$. The result thus indicated that the 'outgroup effect', as indexed by a lower neural response to the pain of the outgroup individual compared to the ingroup individuals, was not present for players of the test game. 

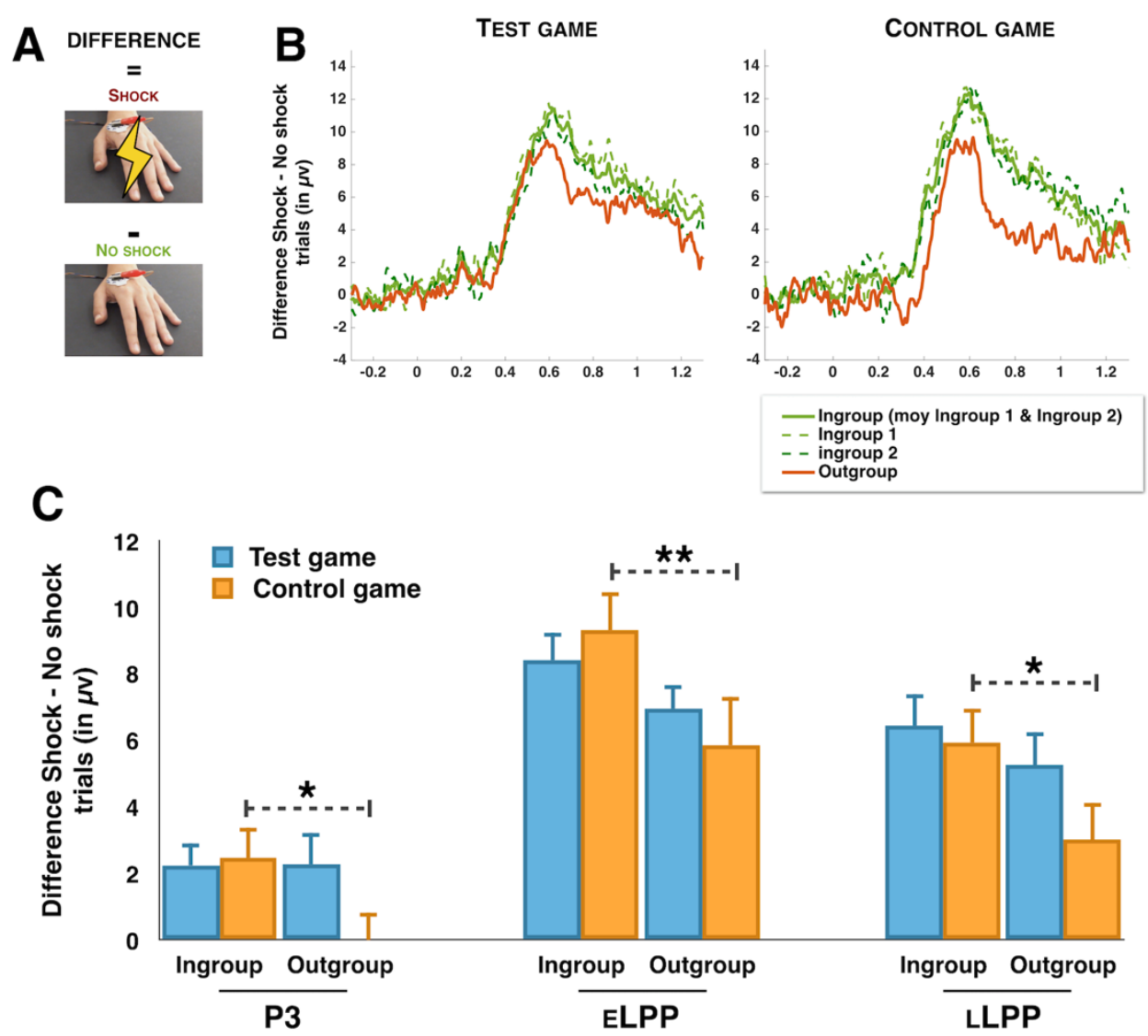

FIGURE 3. A) Computed difference Shock trials (=No helping) - No Shock trials (=Helping). B) Graphical representation of the ERPs for each group and individual. C) Graphical representation of the amplitude in $\mu \mathrm{V}$ of each ERP for the group of players of the test game (in Blue) and players of the control game (in orange). All tests were two-tailed. ** represents $p \geq .001 \& \leq .01$. $*$ represents $p \geq .01 \& \leq .05$.

Temporal binding. It is known that participants may differ in the way they use the scale to provide an answer, some preferring smaller numbers and other preferring larger numbers (Caspar, Lo Bue, et al., 2020; Cravo et al., 2013). We thus transformed the raw interval estimates in z-scored data as they reduce irrelevant inter-subject variability by subtracting from each interval estimate, the mean estimate for that participant across all trials and by dividing the resulting differences by the standard deviation of all estimates for that participant. We conducted a repeated-measures ANOVA with Individual (outgroup, ingroup) and Helping (Helping, No Helping) as within-subject factors and Group (test game, control game) as a between-subject factor on the z-scored interval estimates. We observed a significant triple interaction Individual*Helping ${ }^{*}$ Group $\left(\mathrm{F}_{(1,42)}=6.871, p=.012, \eta^{2}=.141\right)$, see FIGURE 4. When participants decided to help or not the ingroup individuals, z-scored interval estimates did not statistically differ for both players of the test game $(p>.7)$ and players of the control game $(p>.3)$. When participants decided to help or not the outgroup individual, differences in z-scores emerged. Paired sample t-tests indicated that players of the test game had lower z-scored interval estimates, indicating a higher sense of agency, when they helped the outgroup individual $(-.075, \mathrm{SD}=.23)$ compared to when they did not help the outgroup individual (.042, $\mathrm{SD}=.25, \mathrm{t}_{(25)}=-2.575, p=.016$, Cohen's $\left.\mathrm{d}=-.505\right)$. For players of the control game, this difference was not significant $(p>.8)$. 


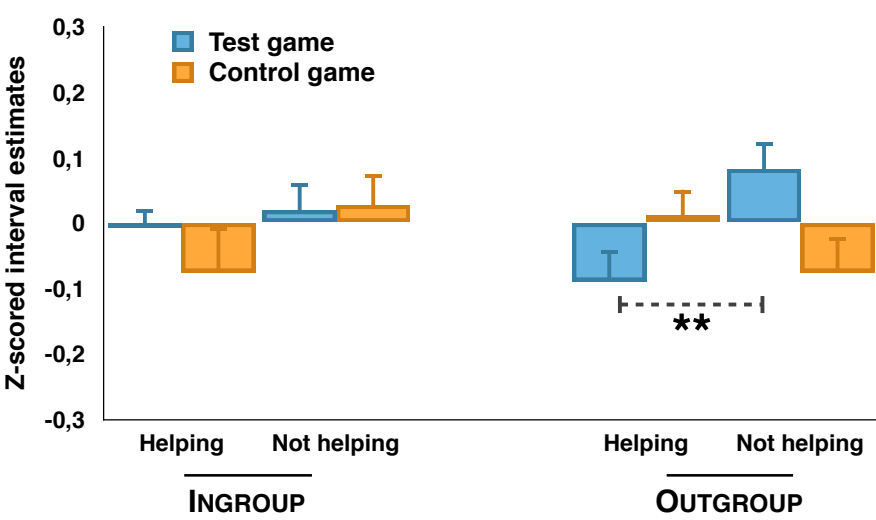

FIGURE 4. Graphical representation of the z-scored interval estimates for the group of players of the test game (in blue) and players of the control game (in orange). All tests were two-tailed. ${ }^{* *}$ represents $p \geq .001 \& \leq .01$.

\section{Intended Prosociality task.}

Prosocial behavior. We conducted a repeated-measures ANOVA with Individual (outgroup, ingroup) as within-subject factor and Group (test game, control game) as a between-subject factor on the number of intended prosocial actions. We observed a main effect of individual $\left(\mathrm{F}_{(1,61)}=18.471, p<.001, \eta_{\mathrm{p}=.232}^{2}\right.$, with a higher number of intended prosocial actions towards the outgroup individual (46, $\mathrm{SD}=7.34)$ than towards the ingroup individuals $(39.9, \mathrm{SD}=3.67)$. The main effect of group $(p>.2)$ and the interaction $(p>.2)$ were not significant.

Time-frequency representation (TFR). We conducted a repeated-measures ANOVA with Individual (outgroup, ingroup) and Condition (Free, Forced) as within-subject factors and Group (test game, control game) as a between-subject factor on the frontal midline theta frequency (FM $\theta)$ power before the keypress (response-locked). Three participants were considered as outliers. None of the main effects or interactions were significant (all $p \mathrm{~s}>.1$ ) Paired comparisons indicated that for players of the test game, the power did not differ between the ingroup individuals and the outgroup individual $(p>.9)$. For players of the control game, the power was higher when they selected the outgroup individual $(.94, \mathrm{SD}=.79)$, suggesting more conflict, than when they selected the ingroup individuals $\left(.63, \mathrm{SD}=.79, \mathrm{t}_{(30)}=2.058, p=.048\right.$, Cohen's d=.370), see FIGURE 5A.

A

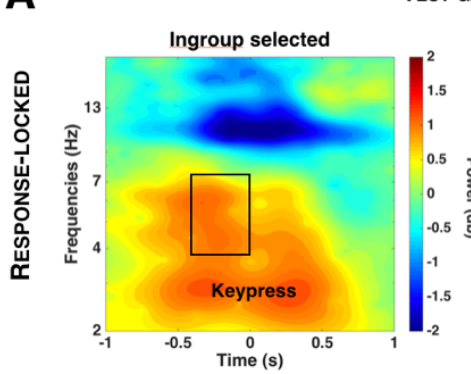

B

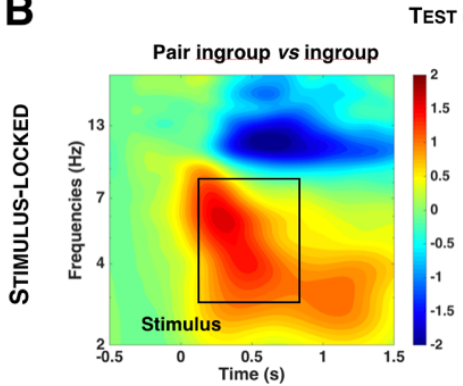

TEST GAME

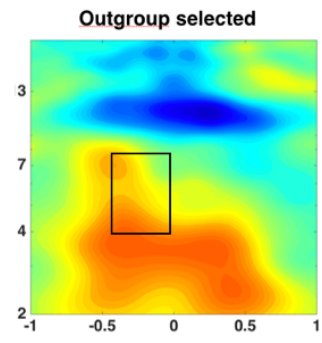

ST GAME
Control game
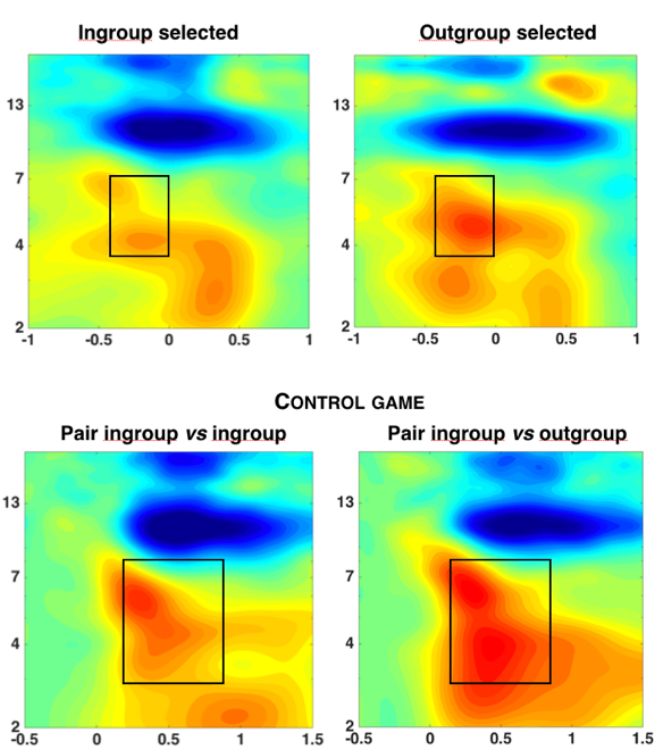
FIGURE 5. A) Response-locked midfrontal theta over the Fz, FC1, FC3, Cz electrodes when participants pressed the key. B) Stimulus-locked midfrontal theta over the Fz, FC1, FC3, Cz electrodes when participants saw the pairs being presented on the screen. The black squares represent the selected time windows based on the significance levels presented on FIGURE 2.

We conducted a repeated-measures ANOVA with Pair (outgroup VS ingroup, ingroup $V S$ ingroup) and Condition (Free, Forced) as within-subject factors and Group (test game, control game) as a between-subject factor on the frontal midline theta frequency (FM $\theta$ ) power after the presentation of the pairs of pictures (stimulus-locked). Three participants were considered as outliers. We observed a significant interaction Pair* Group $\left(\mathrm{F}_{(1,59)}=7.856, p=.007\right.$,

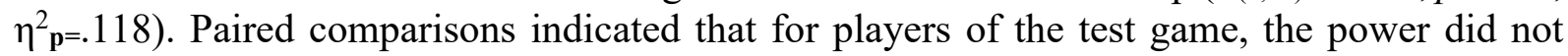
differ between the ingroup individuals and the outgroup individual $(p>.8)$, see FIGURE 5B. For players of the control game, the power was higher when they visualized an outgroup $v s$ an ingroup individual $(1.05, \mathrm{SD}=.68)$, suggesting more conflict, than when they visualized an ingroup $v s$ an ingroup individual $\left(.70, \mathrm{SD}=.86, \mathrm{t}_{(29)}=2.833, p=.008\right.$, Cohen's $\left.\mathrm{d}=.517\right)$. We also observed a significant interaction Condition* Group $\left(\mathrm{F}_{(1,59)}=7.027, p=.01, \eta^{2} \mathrm{p}=.106\right)$, which was not investigated further as not part of our hypothesis. Other main effects or interactions were marginal or not significant (all $p \mathrm{~s} \geq .06$ ).

Reaction Times. We conducted a repeated-measures ANOVA with Individual (outgroup, ingroup) and Condition (Free, Forced) as within-subject factors and Group (test game, control game) as a between-subject factor on the reaction times. We observed a main effect of Condition $\left(\mathrm{F}_{(1,58)}=134.35, p<.001, \eta^{2} \mathbf{p}=.698\right)$, with shorter reaction times in the forced condition (862ms, $\mathrm{SD}=225.1)$ than in the free condition $(1,538 \mathrm{~ms}, \mathrm{SD}=561.25)$. We also observed a main effect of group $\left(\mathrm{F}_{(1,58)}=6.484, p=.014, \eta^{2} \mathrm{p}=.101\right)$, with players of the test game having longer RT than players of the control game. No other main effects or interactions were significant (all $p \mathrm{~s}>.2$ ). None of the paired comparisons indicated an effect of the game on reaction times when selecting the ingroup or the outgroup individuals (all $p \mathrm{~s}>.1$ ).

Correlations. We also conducted exploratory Pearson correlations between reaction times and midfrontal theta power. We observed a positive correlation between reaction times when participants freely decided to select the outgroup individual as the beneficiary of the intended prosocial action and the response-locked midfrontal theta power when they selected the outgroup individual $(\mathrm{r}=.260, p=.045)$. Longer reaction times for selecting the outgroup was thus associated with a higher cognitive conflict. The same correlation when selecting the ingroup individuals was not significant $(p>.5)$.

\section{DISCUSSION}

The present study aimed at investigating the effect of playing a video game designed to reduce prejudice attitudes towards fictional minorities on prejudice towards non-fictional minorities. Overall, we observed encouraging results after playing the game between 2.5 to 4 hours.

In the costly helping task, we observed a typical intergroup empathy bias (Caspar, et al., n.d.; Cikara et al., 2014; Han, 2018) for players of the control game, with a reduced neural response to the pain of the outgroup individual compared to the ingroup individuals on the eLPP and the ILPP. However, we observed that this intergroup empathy bias was not present for players of the test game. This may thus show encouraging results on the possibility to reduce the intergroup empathy bias towards non-fictional minorities after playing a game designed to reduce prejudice towards fictional minorities. Even if we slightly increased our sample size, we nonetheless had to exclude a higher-than-expected number of participants from those analyses as many of them never helped or helped all the time the other (fake) participants. These extreme 
behaviors prevented us to compute a reliable neural response to the pain of others. These results would thus benefit from a replication with a higher number of participants kept for the analysis.

We also observed that players of the test game had lower z-scored interval estimates, interpreted as a higher sense of agency based on the literature (Haggard, 2008, 2017; Moore, 2016), when they helped the outgroup individual by preventing him to receive a painful shock compared to when they did not help him. Interestingly, this effect was not present for players of the control game. Past literature already showed that the sense of agency, as measured through the method of time perception, is higher for actions with positive outcomes for oneself or for others compared to actions with negative outcomes (Caspar et al., 2018; Takahata et al., 2012; Yoshie \& Haggard, 2013). However, those results have not always been replicated (Caspar et al., 2020; Moreton et al., 2017; Moretto et al., 2011) and may reflect differences in experimental set-up regarding the predictability of the outcome (Tanaka \& Kawabata, 2021) or regarding one's own self-judgment about the positivity of the action (Caspar et al., 2016). The present study was not designed to answer this ongoing debate on the effect of outcome valence on the sense of agency but may bring additional evidences that actions that produce positive outcomes for others, even at the expense of its own well-being (i.e. losing a small monetary gain) can lead to an increase in the sense of agency. Numerous studies conducted in psychology and neurosciences have actually shown that prosocial actions are rewarding (Drayton \& Santos). For instance, people tend to report a higher well-being after engaging in prosocial actions such as donations to charity (Thoits \& Hewitt, 2001) or after spending money on others rather than spending money for oneself (Dunn et al., 2008). Neuroscience research has shown that when people make charitable donations, it activates brain regions in the mesolimbic systems associated with reward processing (Moll et al., 2006). It is possible that after playing the test game, participants experienced as more rewarding helping the outgroup than not helping him, as the storyline of the game shows the benefits of helping a fictional minority group for the welfare and prosperity of a fictional society. This increased perception of positivity associated with helping the outgroup may have led to an increase in the sense of agency. However, further studies are necessary to confirm this mediating link.

Curiously, we did not replicate the classical pattern of reduced prosociality towards outgroup individuals compared to ingroup individuals as classically reported in previous studies (Amodio \& Cikara, 2021; Borinca et al., 2021). In the intended prosociality task, the two groups of players selected more frequently the outgroup individual as the recipient of the intended prosocial actions compared to the ingroup individuals. In the costly helping task, the number of helping actions did not differ between the outgroup individual and the ingroup individuals for players of the control game. However, players of the test game helped more the outgroup individual than the ingroup individuals. These two tasks, the costly helping task and the intended prosociality task, differed in the extent to which participants may feel close or distant from the outcomes of their action, as the tasks respectively involve making decisions that have a direct consequence on someone else (i.e. a physical pain), or making decisions that have only imagined consequences on someone else. In the intended prosociality task, there was no implications for choosing the outgroup individual more frequently than the ingroup individuals. As people's decisions may be guided by their willingness to appear fair or good to the experimenter (Franzen \& Pointner, 2012), this may explain why the two groups displayed a higher prosociality towards the outgroup individual compared to the ingroup individuals. However, in the costly helping task, which involves 'real' consequences for oneself and for others, only players of the test game displayed a higher prosociality towards the outgroup individual compared to the ingroup individuals. It may indicate that players of the test game may have experienced a higher willingness not to show prejudice towards outgroup individuals, even are their own expenses (i.e., losing a monetary gain). However, as we did not investigate how participants felt after the experience, this is only an assumption. Such result on the overall 
lack of higher prejudice towards outgroup individuals compared to ingroup individuals would nonetheless deserve more investigation. Our participants were recruited in Brussels, a highlyculturally diverse city and the headquarters of the European Commission and NATO. People living in Brussels are thus frequently in contact with people from highly different cultures and ethnicity. According to the contact hypothesis (Pettigrew, 1986), contacts with outgroup minorities favorize the reduction of prejudice towards outgroup individuals, which may thus explain why we overall did not observe a high prejudice towards outgroup individuals. However, to confirm this hypothesis, the same study should be replicated on individuals coming from less diverse environments. It would also allow to investigate to sizeable impact of the game on different populations.

Interestingly, even though in the intended prosociality task we observed that players of the control game selected more frequently the outgroup individual as the recipient of the intended prosocial actions, we observed that it nonetheless led to a higher cognitive conflict to select the outgroup individual compared to selecting the ingroup individuals. We indeed observed a higher midfrontal theta power prior to the keypress when they selected the outgroup individual compared to selecting the ingroup individuals, an effect that was not present for players of the test game. According to past literature which showed that a stronger conflict elicits a higher activity in the midfrontal theta $(4-8 \mathrm{~Hz})$ compared to low conflicts (Cohen \& Cavanagh, 2011; Cohen, 2014; Cohen \& Ridderinkhof, 2013; Nigbur et al., 2012), it may suggest that players of the control game experienced more conflict when choosing the outgroup over the ingroup and that selecting the outgroup was a less natural behavior. This results is in line with a previous study showing more midfrontal theta activity before selecting an outgroup individual compared to an ingroup individual (Pech \& Caspar, 2022). Interestingly, playing to the test game appears to remove the conflict associated with selecting the outgroup individual compared to the ingroup individuals. We also observed that visualizing an ingroup vs outgroup pair led to a higher midfrontal theta power for players of the control game compared to visualizing an ingroup vs ingroup pair. Again, this difference was not present for players of the test game. Our results tend to show that playing a video game designed to reduce indirectly prejudice towards outgroups has the potential to reduce prejudice, here referring to how much cognitive conflict it involves, towards non-fictional minorities. This result may be important as experiencing a reduced conflict when selecting an action may lead to future changes in behaviors (Amodio, Master, et al., 2008).

The risk taken with using fictional characters in a game is that past literature reported that participants show greater physiological arousal (Lim \& Reeves, 2010) and emotional responses (de Melo et al., 2015) when interacting with humans rather than computer-controlled characters. Our participants only played the single player mode, following the storyline of the main Hero of the game and playing against the computer in the tournaments. It has been suggested that playing against other humans could lead to a greater reduction of prejudice attitudes (Stiff \& Kedra, 2020) because players would enjoy more the games. It would thus be interesting to further test the influence of the test game with its multi-player mode, where players would play against other human beings in the tournaments. However, using fictional characters has the benefit that it could be adapted to any populations without targeting specific ethnic groups, thus leading to a better sizeable impact. Future studies on the reduction of prejudice by using video game should thus favor targeting games using fictional characters rather than non-fictional characters.

The present study thus shows promising results on the possibility to reduce prejudice towards non-fictional minorities by using a video game using fictional minorities. Some limitations have nonetheless to be accounted. First, we do not really know if participants truly believed the cover story regarding the presence of others real participants performing the task at the same time. The majority of them reported verbally at the end of the experiment that they 
did not guess about this experimental trick, but we did not conduct a systematic interview, thus precluding to know if this applies to all our participants or not. We nonetheless tried to restrict the possibility for participants to guess the aim of the study, by including two ingroup individuals and a single outgroup individual, instead of an ingroup individual alone versus an outgroup individual alone. A second limitation is that we do not know about the initial prejudice attitudes of our participants towards outgroup individuals, before playing the game. A more rigorous assessment of the impact of the game could have involved performing the same tasks before and after playing the game and including a re-test control group for evaluating the effect of performing the same tasks twice. Third, similar to the huge majority of studies on the impact of different interventions on reducing prejudice towards outgroup members (Paluck et al., 2021), we did not investigate the long-term effects of the game, thus precluding conclusions on the sustainability of the intervention. A critical societal challenge consists in evaluating the potential long-term effects of interventions aiming at reducing prejudice and future studies should also include a longitudinal assessment of their effects.

Acknowledgments. The study is funded by an ISF-Police Action Grant (grant number 867460) from the European Commission. The authors thank Georges Weiss and Radio La Benevolencija for their support during the project.

Authors contribution. E.A.C. and G.P.P developed the study concept and the study design. G.P.P recruited and tested participants. E.A.C. and G.P.P. analyzed the results. E.A.C. wrote the first draft of the manuscript and G.P.P. provided comments. The two authors approved the final version of the manuscript.

Data availability. Data and scripts are made available on OSF (DOI 10.17605/OSF.IO/9CJME).

\section{Bibliography}

- Adachi, P. J. C., Hodson, G., \& Hoffarth, M. R. (2015). Video game play and intergroup relations: Real world implications for prejudice and discrimination. Aggression and Violent Behavior, 25, 227-236. https://doi.org/10.1016/j.avb.2015.09.008

- Adachi, P. J. C., Hodson, G., Willoughby, T., Blank, C., \& Ha, A. (2016). From outgroups to allied forces: Effect of intergroup cooperation in violent and nonviolent video games on boosting favorable outgroup attitudes. Journal of Experimental Psychology: General, 145(3), 259-265. https://doi.org/10.1037/xge0000145

- Adachi, P. J. C., Hodson, G., Willoughby, T., \& Zanette, S. (2015). Brothers and sisters in arms: Intergroup cooperation in a violent shooter game can reduce intergroup bias. Psychology of Violence, 5(4), 455-462. https://doi.org/10.1037/a0037407

- Amodio, D. M., \& Cikara, M. (2021). The Social Neuroscience of Prejudice. Annual Review of Psychology, 72(1), 439-469. https://doi.org/10.1146/annurev-psych-010419050928

- Amodio, D. M., Devine, P. G., \& Harmon-Jones, E. (2008). Individual differences in the regulation of intergroup bias: The role of conflict monitoring and neural signals for control. Journal of Personality and Social Psychology, 94(1), 60-74. https://doi.org/10.1037/00223514.94.1.60

- Amodio, D. M., Kubota, J. T., Harmon-Jones, E., \& Devine, P. G. (2006). Alternative mechanisms for regulating racial responses according to internal vs external cues. Social Cognitive and Affective Neuroscience, 1(1), 26-36. https://doi.org/10.1093/scan/nsl002

- Amodio, D. M., Master, S. L., Yee, C. M., \& Taylor, S. E. (2008). Neurocognitive components of the behavioral inhibition and activation systems: Implications for theories of self-regulation. Psychophysiology, 45(1), 11-19. https://doi.org/10.1111/j.14698986.2007.00609.x

- Amodio, D. M., \& Swencionis, J. K. (2018). Proactive control of implicit bias: A theoretical model and implications for behavior change. Journal of Personality and Social 
Psychology, 115(2), 255-275. https://doi.org/10.1037/pspi0000128

- Bartholow, B. D., Dickter, C. L., \& Sestir, M. A. (2006). Stereotype activation and control of race bias: Cognitive control of inhibition and its impairment by alcohol. Journal of Personality and Social Psychology, 90(2), 272-287. https://doi.org/10.1037/00223514.90.2.272

- Berns, G. S., Cohen, J. D., \& Mintun, M. A. (1997). Brain Regions Responsive to Novelty in the Absence of Awareness. Science. https://doi.org/10.1126/science.276.5316.1272

- Berry, D. R., Wall, C. S. J., Tubbs, J. D., Zeidan, F., \& Brown, K. W. (2021). Short-Term Training in Mindfulness Predicts Helping Behavior Toward Racial Ingroup and Outgroup Members. Social Psychological and Personality Science, 19485506211053096. https://doi.org/10.1177/19485506211053095

- Blair, I. V. (2002). The Malleability of Automatic Stereotypes and Prejudice. Personality and Social Psychology Review, 6(3), 242-261. https://doi.org/10.1207/S15327957PSPR0603_8

- Borinca, I., Falomir-Pichastor, J. M., Andrighetto, L., \& Durante, F. (2021). Outgroup prejudice and perceptions of prosocial intergroup behaviors. European Journal of Social Psychology, 51(1), 40-53. https://doi.org/10.1002/ejsp.2712

- Cameron, L., Rutland, A., Brown, R., \& Douch, R. (2006). Changing Children's Intergroup Attitudes Toward Refugees: Testing Different Models of Extended Contact. Child Development, 77(5), 1208-1219. https://doi.org/10.1111/j.1467-8624.2006.00929.x

- Cary, L. A. (2017). The Predictors and Consequences of Prejudice in Online Video Games [Thesis]. https://tspace.library.utoronto.ca/handle/1807/80846

- Caspar, E. A., Christensen, J. F., Cleeremans, A., \& Haggard, P. (2016). Coercion Changes the Sense of Agency in the Human Brain. Current Biology, 26(5), 585-592. https://doi.org/10.1016/j.cub.2015.12.067

- Caspar, E. A., Cleeremans, A., \& Haggard, P. (2018). Only giving orders? An experimental study of the sense of agency when giving or receiving commands. PLOS ONE, 13(9), e0204027. https://doi.org/10.1371/journal.pone.0204027

- Caspar, E. A., Lo Bue, S., Magalhães De Saldanha da Gama, P. A., Haggard, P., \& Cleeremans, A. (2020). The effect of military training on the sense of agency and outcome processing. Nature Communications, 11(1), 4366. https://doi.org/10.1038/s41467-02018152-X

- Caspar, E.A., Pech, G.P., Gishoma, D., \& Kanazayire, C. (n.d.). On the modulation of empathy for pain between genocide survivors, former perpetrators, victims and their children in Rwanda. Under Review.

- Cavanagh, J. F., \& Frank, M. J. (2014). Frontal theta as a mechanism for cognitive control. Trends in Cognitive Sciences, 18(8), 414-421. https://doi.org/10.1016/j.tics.2014.04.012

- Cikara, M., Bruneau, E., Van Bavel, J. J., \& Saxe, R. (2014). Their pain gives us pleasure: How intergroup dynamics shape empathic failures and counter-empathic responses. Journal of Experimental Social Psychology, 55, 110-125. https://doi.org/10.1016/j.jesp.2014.06.007

- Cohen, M., \& Cavanagh, J. F. (2011). Single-Trial Regression Elucidates the Role of Prefrontal Theta Oscillations in Response Conflict. Frontiers in Psychology, 2, 30. https://doi.org/10.3389/fpsyg.2011.00030

- Cohen, M. X. (2014). A neural microcircuit for cognitive conflict detection and signaling. Trends in Neurosciences, 37(9), 480-490. https://doi.org/10.1016/j.tins.2014.06.004

- Cohen, M. X., \& Donner, T. H. (2013). Midfrontal conflict-related theta-band power reflects neural oscillations that predict behavior. Journal of Neurophysiology, 110(12), 2752-2763. https://doi.org/10.1152/jn.00479.2013

- Cohen, M. X., \& Ridderinkhof, K. R. (2013). EEG Source Reconstruction Reveals Frontal- 
Parietal Dynamics of Spatial Conflict Processing. PLOS ONE, 8(2), e57293. https://doi.org/10.1371/journal.pone.0057293

- Coll, M.-P. (2018). Meta-analysis of ERP investigations of pain empathy underlines methodological issues in ERP research. Social Cognitive and Affective Neuroscience, 13(10), 1003-1017. https://doi.org/10.1093/scan/nsy072

- Correll, J., Urland, G. R., \& Ito, T. A. (2006). Event-related potentials and the decision to shoot: The role of threat perception and cognitive control. Journal of Experimental Social Psychology, 42(1), 120-128. https://doi.org/10.1016/j.jesp.2005.02.006

- Crisp, R. J., \& Turner, R. N. (2009). Can imagined interactions produce positive perceptions?: Reducing prejudice through simulated social contact. American Psychologist, 64(4), 231-240. https://doi.org/10.1037/a0014718

- de Melo, C. M., Gratch, J., \& Carnevale, P. J. (2015). Humans versus Computers: Impact of Emotion Expressions on People's Decision Making. IEEE Transactions on Affective Computing, 6(2), 127-136. https://doi.org/10.1109/TAFFC.2014.2332471

- Dunn, E. W., Aknin, L. B., \& Norton, M. I. (2008). Spending Money on Others Promotes Happiness. Science. https://doi.org/10.1126/science.1150952

- Ellison, C. G., Shin, H., \& Leal, D. L. (2011). The Contact Hypothesis and Attitudes Toward Latinos in the United States. Social Science Quarterly, 92(4), 938-958. https://doi.org/10.1111/j.1540-6237.2011.00798.x

- Faul, F., Erdfelder, E., Lang, A.-G., \& Buchner, A. (2007). G*Power 3: A flexible statistical power analysis program for the social, behavioral, and biomedical sciences. Behavior Research Methods, 39(2), 175-191. https://doi.org/10.3758/BF03193146

- Franzen, A., \& Pointner, S. (2012). Anonymity in the dictator game revisited. Journal of Economic Behavior \& Organization, 81(1), 74-81. https://doi.org/10.1016/j.jebo.2011.09.005

- Gallagher, S. (2000). Gallagher, S. 2000. Philosophical conceptions of the self: Implications for cognitive science. Trends in Cognitive Sciences, 4, 14-21.

- Greene, J. D., Nystrom, L. E., Engell, A. D., Darley, J. M., \& Cohen, J. D. (2004). The Neural Bases of Cognitive Conflict and Control in Moral Judgment. Neuron, 44(2), 389400. https://doi.org/10.1016/j.neuron.2004.09.027

- Greenwald, A. G., \& Pettigrew, T. F. (2014). With malice toward none and charity for some: Ingroup favoritism enables discrimination. American Psychologist, 69(7), 669-684. https://doi.org/10.1037/a0036056

- Haggard, P. (2008). Human volition: Towards a neuroscience of will. Nature Reviews Neuroscience, 9(12), 934-946. https://doi.org/10.1038/nrn2497

- Haggard, P. (2017). Sense of agency in the human brain. Nature Reviews Neuroscience, 18(4), 196-207. https://doi.org/10.1038/nrn.2017.14

- Han, S. (2018). Neurocognitive Basis of Racial Ingroup Bias in Empathy. Trends in Cognitive Sciences, 22(5), 400-421. https://doi.org/10.1016/j.tics.2018.02.013

- Hein, G., Silani, G., Preuschoff, K., Batson, C. D., \& Singer, T. (2010). Neural Responses to Ingroup and Outgroup Members' Suffering Predict Individual Differences in Costly Helping. Neuron, 68(1), 149-160. https://doi.org/10.1016/j.neuron.2010.09.003

- Hess, A., Iyer, H., \& Malm, W. (2001). Linear trend analysis: A comparison of methods. Atmospheric Environment, 35(30), 5211-5222. https://doi.org/10.1016/S13522310(01)00342-9

- Jahnke, S., Schröder, C. P., Goede, L.-R., Lehmann, L., Hauff, L., \& Beelmann, A. (2020). Observer Sensitivity and Early Radicalization to Violence Among Young People in Germany. Social Justice Research, 33(3), 308-330. https://doi.org/10.1007/s11211-02000351-y

- Lamm, C., Decety, J., \& Singer, T. (2011). Meta-analytic evidence for common and 
1 distinct neural networks associated with directly experienced pain and empathy for pain.

2 NeuroImage, 54(3), 2492-2502. https://doi.org/10.1016/j.neuroimage.2010.10.014

- Leys, C., Ley, C., Klein, O., Bernard, P., \& Licata, L. (2013). Detecting outliers: Do not use standard deviation around the mean, use absolute deviation around the median. Journal of Experimental Social Psychology, 49(4), 764-766.

https://doi.org/10.1016/j.jesp.2013.03.013

- Lim, S., \& Reeves, B. (2010). Computer agents versus avatars: Responses to interactive game characters controlled by a computer or other player. International Journal of HumanComputer Studies, 68(1), 57-68. https://doi.org/10.1016/j.ijhcs.2009.09.008

- Miller, N., \& Brewer, M. B. (1986). Categorization effects on ingroup and outgroup perception. In Prejudice, discrimination, and racism (pp. 209-230). Academic Press.

- Moll, J., Krueger, F., Zahn, R., Pardini, M., Oliveira-Souza, R. de, \& Grafman, J. (2006). Human fronto-mesolimbic networks guide decisions about charitable donation. Proceedings of the National Academy of Sciences, 103(42), 15623-15628. https://doi.org/10.1073/pnas.0604475103

- Moore, J. W. (2016). What Is the Sense of Agency and Why Does it Matter? Frontiers in Psychology, 0. https://doi.org/10.3389/fpsyg.2016.01272

- Moore, J. W., \& Haggard, P. (2010). Intentional Binding and Higher Order Agency Experience. Consciousness and Cognition, 19(1), 490-491. https://doi.org/10.1016/j.concog.2009.11.007

- Moreton, J., Callan, M. J., \& Hughes, G. (2017). How much does emotional valence of action outcomes affect temporal binding? Consciousness and Cognition, 49, 25-34. https://doi.org/10.1016/j.concog.2016.12.008

- Moretto, G., Walsh, E., \& Haggard, P. (2011). Experience of agency and sense of responsibility. Consciousness and Cognition, 20(4), 1847-1854. https://doi.org/10.1016/j.concog.2011.08.014

- Nieuwenhuis, S., Ridderinkhof, K. R., Blom, J., Band, G. P. H., \& Kok, A. (2001). Errorrelated brain potentials are differentially related to awareness of response errors: Evidence from an antisaccade task. Psychophysiology, 38(5), 752-760. https://doi.org/10.1111/14698986.3850752

- Nigbur, R., Cohen, M. X., Ridderinkhof, K. R., \& Stürmer, B. (2012). Theta Dynamics Reveal Domain-specific Control over Stimulus and Response Conflict. Journal of Cognitive Neuroscience, 24(5), 1264-1274. https://doi.org/10.1162/jocn_a_00128

- Oostenveld, R., Fries, P., Maris, E., \& Schoffelen, J.-M. (2011). FieldTrip: Open source software for advanced analysis of MEG, EEG, and invasive electrophysiological data. Computational Intelligence and Neuroscience, 2011, 156869. https://doi.org/10.1155/2011/156869

- Ortiz, S. M. (2019). "You Can Say I Got Desensitized to It": How Men of Color Cope with Everyday Racism in Online Gaming. Sociological Perspectives, 62(4), 572-588. https://doi.org/10.1177/0731121419837588

- Paluck, E. L., \& Green, D. P. (2009a). Prejudice Reduction: What Works? A Review and Assessment of Research and Practice. Annual Review of Psychology, 60(1), 339-367. https://doi.org/10.1146/annurev.psych.60.110707.163607

- Paluck, E. L., \& Green, D. P. (2009b). Deference, Dissent, and Dispute Resolution: An Experimental Intervention Using Mass Media to Change Norms and Behavior in Rwanda. American Political Science Review, 103(4), 622-644. https://doi.org/10.1017/S0003055409990128

- Paluck, E. L., Porat, R., Clark, C. S., \& Green, D. P. (2021). Prejudice Reduction: Progress and Challenges. Annual Review of Psychology, 72(1), null. https://doi.org/10.1146/annurev-psych-071620-030619 
- Pech, G., \& Caspar, E. A. (2022). Intended prosociality between former genocide perpetrators, survivors and their children in Rwanda. PsyArXiv.

- Pettigrew, T. F. (1986). The intergroup contact hypothesis reconsidered. In Contact and conflict in intergroup encounters (pp. 169-195). Basil Blackwell.

- Robinson, N., \& Whittaker, J. (2021). Playing for Hate? Extremism, Terrorism, and Videogames. Studies in Conflict \& Terrorism, $0(0), 1-36$. https://doi.org/10.1080/1057610X.2020.1866740

- Saleem, M., \& Anderson, C. A. (2013). Arabs as terrorists: Effects of stereotypes within violent contexts on attitudes, perceptions, and affect. Psychology of Violence, 3(1), 84-99. https://doi.org/10.1037/a0030038

- Semmelmann, K., \& Weigelt, S. (2017). Online psychophysics: Reaction time effects in cognitive experiments. Behavior Research Methods, 49(4), 1241-1260. https://doi.org/10.3758/s13428-016-0783-4

- Seo, S. (2006). A Review and Comparison of Methods for Detecting Outliers in Univariate Data Sets. Undefined. https://www.semanticscholar.org/paper/A-Review-and-Comparisonof-Methods-for-Detecting-in-Seo/cb868f0b242b9623b7544a58b6a21647dfa138a5

- Stephan, W. G., \& Finlay, K. (1999). The role of empathy in improving intergroup relations. Journal of Social Issues, 55(4), 729-743. https://doi.org/10.1111/00224537.00144

- Stiff, C., \& Bowen, T. (2016). Two-Player Game: Playing Casual Video Games with Outgroup Members Reduces Levels of Prejudice Toward That Outgroup. International Journal of Human-Computer Interaction, 32(12), 912-920. https://doi.org/10.1080/10447318.2016.1212484

- Stiff, C., \& Kedra, P. (2020). Playing well with others: The role of opponent and intergroup anxiety in the reduction of prejudice through collaborative video game play. Psychology of Popular Media, 9(1), 105-115. https://doi.org/10.1037/ppm0000210

- Tajfel, H. (1970). Experiments in Intergroup Discrimination. Scientific American, 223(5), 96-103.

- Takahata, K., Takahashi, H., Maeda, T., Umeda, S., Suhara, T., Mimura, M., \& Kato, M. (2012). It's Not My Fault: Postdictive Modulation of Intentional Binding by Monetary Gains and Losses. PLOS ONE, 7(12), e53421.

https://doi.org/10.1371/journal.pone.0053421

- Tanaka, T., \& Kawabata, H. (2021). Sense of agency is modulated by interactions between action choice, outcome valence, and predictability. Current Psychology, 40(4), 1795-1806. https://doi.org/10.1007/s12144-018-0121-3

- Thoits, P. A., \& Hewitt, L. N. (2001). Volunteer Work and Well-Being. Journal of Health and Social Behavior, 42(2), 115-131. https://doi.org/10.2307/3090173

- Timmers, I., Park, A. L., Fischer, M. D., Kronman, C. A., Heathcote, L. C., Hernandez, J. M., \& Simons, L. E. (2018). Is Empathy for Pain Unique in Its Neural Correlates? A MetaAnalysis of Neuroimaging Studies of Empathy. Frontiers in Behavioral Neuroscience, 12, 289. https://doi.org/10.3389/fnbeh.2018.00289

- Vang, M. H., \& Fox, J. (2014). Race in Virtual Environments: Competitive Versus Cooperative Games with Black or White Avatars. Cyberpsychology, Behavior, and Social Networking, 17(4), 235-240. https://doi.org/10.1089/cyber.2013.0289

- Wham, M. A., \& Others, A. (1996). Enhancing Multicultural Awareness through the Storybook Reading Experience. Journal of Research and Development in Education, 30(1), 1-9.

- Yang, G. S., Gibson, B., Lueke, A. K., Huesmann, L. R., \& Bushman, B. J. (2014). Effects of Avatar Race in Violent Video Games on Racial Attitudes and Aggression. Social Psychological and Personality Science, 5(6), 698-704. 
1 https://doi.org/10.1177/1948550614528008

2 - Yoshie, M., \& Haggard, P. (2013). Negative Emotional Outcomes Attenuate Sense of 3 Agency over Voluntary Actions. Current Biology, 23(20), 2028-2032.

4 https://doi.org/10.1016/j.cub.2013.08.034 